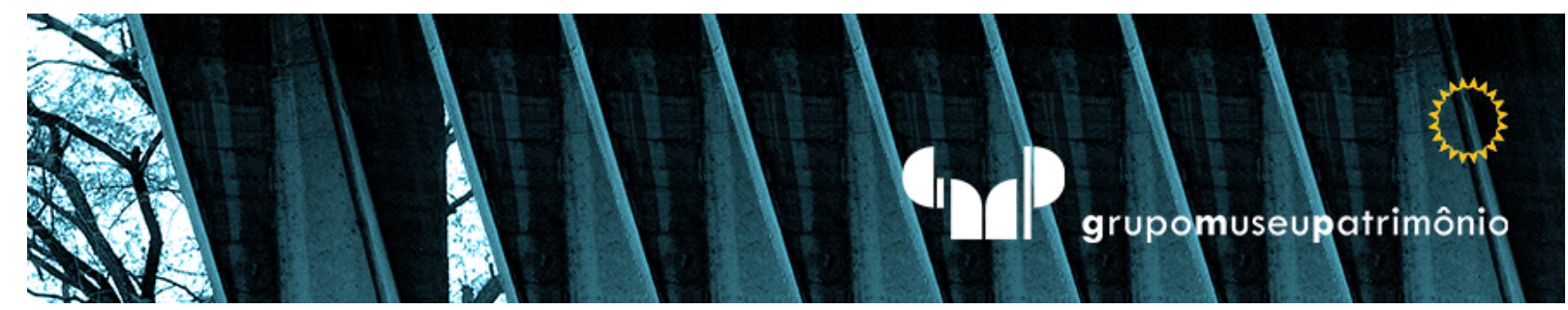

\title{
De convidado a anfitrião - a ânima local do CCBB Brasília
}

\author{
De invitado a anfitrión - el ánimo local del \\ CCBB Brasília
}

\section{From guest to hold - the local spirit of the CCBB Brasília}

Adelaide Cristina Nascimento de Oliveira Jornalista e Mestre em Turismo pela Universidade de Brasília

(UnB), Brasilia, Brasil. adecno@gmail.com

\section{Eloisa Pereira Barroso}

Professora Doutora do Departamento de História da Universidade de Brasília (UnB), Brasília, Brasil. eloisabarroso@unb.br 


\section{Resumo}

O turista/visitante do Centro Cultural Banco do Brasil Brasília (CCBB) ressignifica os espaços enquanto o Centro, como anfitrião, adapta-se a essa necessidade. Este artigo repercute como a movimentação do espaço modificou o relacionamento da sociedade e do próprio mecenas, o Banco do Brasil, com o CCBB. E isso levando-se em conta o turismo e seu valor simbólico sobre um ambiente outrora inóspito e atualmente vivaz em seus lugares em constante transmutação. $O$ texto ainda aborda o que leva uma instituição financeira a investir em um segmento que não é o seu, concentrando recursos em espaços com equipamentos próprios, prevendo programação regular e diversificada. O tão aclamado "sinta-se em casa" pode tornar o visitante indesejado, caso não aceite as regras do lugar - e ele tem inúmeras formas de fazê-lo. No entanto, o CCBB ocupou o Edifício Tancredo Neves, tornando-se um dos sítios mais aprazíveis na capital federal, ao transformar-se continuamente. $\mathrm{O}$ fato custou ao prédio o próprio nome, pois todos os que buscam pela programação cultural oferecida não se referem ao complexo pelo seu nome de batismo. $O$ conjunto arquitetônico, inaugurado para ser o centro de formação dos funcionários do Banco do Brasil, tornou-se sinônimo de lazer voltado para os mais diversos públicos. O fluxo de visitantes é constante, ao ponto de transformar o CCBB DF no segundo museu/centro cultural mais visitado do Brasil. Sua hospitalidade é um elemento reconhecido e reforçado, seja na imprensa, nas mídias e redes sociais e, especialmente, nas manifestações dos visitadores. Nas reflexões sobre espaço, paisagem, território e lugar reconhece-se o ambiente como produtor de algo singular, que existe em função de construções de memória coletiva - e tal se dá em função da apropriação do CCBB pelo cidadão.

Palavras-Chave: Museu. CCBB. Brasília. Cultura. Paisagem.

\section{Resumen}

El turista / visitante del Centro Cultural Banco do Brasil Brasília resignifica los espacios mientras que el Centro, como anfitrión, se adapta a esa necesidad. Este artícolo refleja cómo el movimiento del espacio cambió la relación entre la sociedad y el patrón, Banco do Brasil, con el CCBB. Y esto está teniendo en cuenta el turismo y su valor simbólico en un ambiente uma vez inhóspito y actualmente vivaz en sus lugares de transmutación constante. El texto sigue debatendo qué es lo que lleva a una instituición financeira a invertir en un segmento que no es suyo, concentrando las inversiones en espacios con equipo próprio, prediciendo la programación regular y diversificada. El tan aclamado "siéntase como en casa" puede hacer que el visitante no sea deseado si no acepta las reglas del lugar - y él tiene muchas maneras de hacerlo. Sin embargo, el CCBB ocupó el edificio Tancredo Neves, convirtiéndose en uno de los sítios más agradables de la capital federal. El hecho costó al edificio su propio nombre, porque todos aquellos que buscan 
por la programación cultural ofrecida no se refieren al complejo por su nombre de bautismo. El conjunto arquitectónico, inaugurado para ser el centro de formación de los empleados del Banco do Brasil, se convirtió en sinónimo de ocio centrado en las más diversas audiências. El flujo de visitantes es constante, hasta el punto de transformar el CCBB/DF em el segundo Museo/Centro Cultural más visitado en Brasil. Su hospitalidad es un elemento reconocido y reforzado, ya sea en la prensa, en los médios de comunicación y en las redes sociales y, especialmente, en las demonstraciones de los visitantes. En las reflexiones sobre el espacio, paisaje, territorio y lugar, se reconoce el ambiente como productor de algo singular, que existe en función de construcciones de memoria colectiva - y esto se debe a la apropiación de CCBB por el ciudadano.

Palabras-Clave: Museo. CCBB. Brasília. Cultura. Paisaje.

\begin{abstract}
The tourist / visitor of the Centro Cultural Banco do Brasil Brasília remeans the spaces while the Center, as a host, customizes itself adapting to this need. This article reflects how the movement of space changed the relationship between society and the patron, Banco do Brasil, with the CCBB, to invest in a segment that has nothing to do with its own business, putting money in spaces with its own equipment, with a regular and diversified programming. The so acclaimed "feel at home" can make the visitor unwanted if he does not accept the rules of the place - and he has many ways to do that. However, the CCBB has been occupied the Tancredo Neves building, becoming one of the most pleasant places in the federal capital, by continually becoming. The fact cost the building its own name, because all who seek the cultural program offered or even have a picnic or meditate do not refer to the complex by its name of baptism. The CCBB became synonymous of leisure by continually transforming its space. The architectural ensemble was created in the 1990's to be the training center for Banco do Brasil employees and a little more than 10 years later, it occupies almost the whole space formed by 23 thousand square meters. The flow of visitors is constant, raising the CCBB DF to the second most visited museum / cultural center in Brazil. Its hospitality is a recognized and reinforced element, whether in the press, in the media and social networks and, especially, in the demonstrations of its audience. In the reflections about space, landscape, territory and place, one recognizes the ambience as producer of something singular, that exists because of the construction of collective memory - and this is due to its appropriation by the citizen.
\end{abstract}

Keywords: Museum. CCBB. Brasilia. Culture. Landscape. 


\section{DE CONVIDADO A ANFITRIÃO - A ÂNIMA LOCAL DO CCBB BRASÍLIA}

Não precisa pressa porque os lugares estão parados. Os lugares estão no lugar porque não precisa pressa.

Arnaldo Antunes

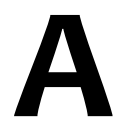
reflexão aqui realizada parte do princípio de que o mundo vive sob o efeito de inferências. As observações sobre espaço, paisagem, território e lugar reconhecem o ambiente como produtor de algo singular, que existe em função de construções de memória coletiva - e tal se dá devido à sua apropriação pelo cidadão. O turista ou visitante do Centro Cultural Banco do Brasil de Brasília (Centro, CCBB, CCBB DF ou CCBB Brasília) ressignifica os espaços enquanto o Centro, como anfitrião, adapta-se a essa necessidade ${ }^{1}$.

\footnotetext{
${ }^{1}$ Este artigo contém recorte da dissertação de Mestrado O CCBB como anfitrião: uma reflexão sobre o turismo e a hospitalidade a partir do discurso proferido pelo Centro Cultural Banco do Brasil Brasília no site e no Facebook, defendida pela autora, Adelaide C. N. Oliveira, em março de 2016, na Universidade de Brasília (UnB), tendo como orientadora a coautora, Eloisa P. Barroso.
} 
O crescente público frequentador do CCBB demonstra que o espaço vem atendendo as expectativas dos seus visitantes, pois, na fragmentada sociedade contemporânea, com acesso à informação pelos diversos meios de comunicação, o indivíduo pode escolher livremente o que fazer para ocupar seu tempo livre. E o Centro brasiliense tem sido essa opção para muitos.

Apesar da redundância, é preciso lembrar que Brasília, por si só, é uma cidade que atrai turistas do Brasil e do mundo a partir de diferentes motivações: seu status de capital federal, a curiosidade de ter sido construída em cinco anos, pelos monumentos e edifícios de Niemeyer ou mesmo pelo traçado urbanístico de Lúcio Costa. Inúmeros estudos dão conta da personalidade e das facetas da capital, aos quais não iremos nos ater. Centremos no CCBB DF e seus domínios - a caracterizá-lo como turístico, como na descrição de Yázigi.

\begin{abstract}
A região turística corresponde a uma área com certa densidade de frequentação, serviços e equipamentos turísticos e com uma imagem que lhe caracteriza. Às vezes se confunde ou se identifica com um conjunto natural, em cujo interior se circunscreve, como nos núcleos urbanos ou focos de frequentação turística litorâneos, localizados em diversos municípios limítrofes e pertencentes a um mesmo conjunto geográfico. É possível distinguir pelo menos três tipos de regiões turísticas: a) os âmbitos espaciais considerados a priori, onde existem atividades turísticas suscetíveis de serem analisadas; b) as regiões homogêneas; e c) as unidades administrativas consideradas regiões turísticas. (Yázigi, 2001, p. 33-34)
\end{abstract}

No CCBB, o projeto paisagístico de Alda Rabelo Cunha, com as árvores e um amplo jardim esverdeado, ao longo de $23 \mathrm{~m}^{2}$, mantém destacado o conjunto arquitetônico de concreto concebido por Oscar Niemeyer. Tais estruturas ganham denominações e funções distintas das ciências. Espaço, paisagem, território e lugar são elementos caros para Milton Santos, para os quais o mestre dedicou boa parte de suas reflexões metodológicas.

Paisagem e espaço não são sinônimos. A paisagem é o conjunto de formas que, num dado momento, exprimem as heranças que representam as sucessivas relações localizadas entre homem e natureza. O espaço são essas formas mais a vida que as anima. (Santos, 2006, p. 66)

O geógrafo prossegue: 
A palavra paisagem é frequentemente utilizada em vez da expressão configuração territorial. Esta é o conjunto de elementos naturais e artificiais que fisicamente caracterizam uma área. A rigor, a paisagem é apenas a porção da configuração territorial que é possível abarcar com a visão.[...] (op. cit., p. 67)

Neste contexto, todo o complexo do CCBB (jardins, construções, a vista para o horizonte etc.) compõe sua paisagem, a qual vem se modificando ao longo dos anos: o próprio edifício de concreto, o terreno e suas exposições permanentes e temporárias, apresentações de artes cênicas e musicais, cinema ao ar livre, sua praça... São as formas que caracterizam a paisagem e configuram seu caráter histórico. Já o espaço,

[...] uno e múltiplo, por suas diversas parcelas, e através do seu uso, é um conjunto de mercadorias, cujo valor individual é função do valor que a sociedade, em um dado momento, atribui a cada pedaço de matéria, isto é, cada fração da paisagem. (Santos, 2006, p. 67)

Assim, o Centro tem como espaços os dois teatros, as quatro galerias, o pavilhão de vidro, o Museu, cada qual com sua função, com seu uso e valores atribuídos. Logo, pode-se dizer que "paisagem e espaço são um par dialético" (Santos, 2008, 79) indissociáveis no CCBB.

O turista/visitante do Centro se organiza e se (re)organiza nos espaços que se tornam significativos para ele a partir do momento em que tanto pode usufruir da programação oferecida quanto criar seu próprio modo de estar no espaço. Como exemplo dessa adequação, o público ocupou o CCBB para venerar a natureza nas meditações da lua cheia, sendo a beleza da vegetação e a vista para o lago Paranoá provas materiais dessa percepção pública, sem que houvesse para tal chamamento por parte do Centro. Também os piqueniques, realizados especialmente nos fins de semana, começaram e permanecem como ações espontâneas dos visitantes, não integrando nenhum calendário oficial do Centro. E aqui cabe uma questão: em que medida se dá esta apropriação do espaço, sendo o CCBB um território privado?

Na visão do público, porém, tudo deve ser aproveitado, principalmente a paisagem. De maneira planejada ou Ihana, natural, como anfitrião, o CCBB 
adapta-se para fornecer tanto conteúdo às formas de seu ambiente quanto infraestrutura aos seus frequentadores. Nessa perspectiva, a instituição financeira cria uma cadeia discursiva na qual aquele que visita o Centro tem a sensação de poder se apropriar do espaço de maneira a vivenciar suas experiências e subjetividades como se aquele lugar a ele pertencesse.

Milton Santos defende que o espaço não pode ser estudado sem se observar também o homem e as instituições que o rodeiam. Daí serem as indagações sobre "a alma do lugar", de Yázigi, imprescindíveis para auxiliar a investigação a identificar como se dá o reconhecimento do CCBB como lugar de visitação e acolhimento. Eis uma das premissas deste estudo, que, ainda que esbarre na lógica econômica, tendo em vista o escopo e a origem dos recursos de seu principal mecenas, abre a possibilidade de se tratar o discurso do CCBB DF no que tange à necessidade de se desenvolver uma programação cultural eficaz, ao intuito de reforçar seu papel junto à sociedade local, como espaço de encontro, de reorganização de laços de sociabilidade e de reafirmação de poder, na acepção de Michel Foucault.

Seria ingenuidade não perceber que as ações voltadas para a cultura e o turismo não estariam vinculadas aos princípios do mercado. 0 pensamento vai ao encontro da essência do controlador do CCBB. Instalar-se na capital federal possibilitou ao Banco do Brasil fazer-se presença em um lugar que reforçaria o seu poder simbólico. Por meio da cultura, O BB, possuidor do faro do contemporâneo, se insere na praxis transformadora e modernizante da cidade. Como CCBB, a Empresa não só presta serviços, mas apresenta-se à sociedade como anfitrião de um território que tem se tornado, a cada ano, mais hospitaleiro - que pertence ao indivíduo que o frequenta e vice-versa.

O número de visitantes que o CCBB ostenta indica que ir ao local tornou-se um costume do brasiliense. E como lembram Botton et al (2014, p. 59), "o hábito é o mecanismo pelo qual o comportamento se torna automático em várias áreas do nosso funcionamento." Vê-se, aí, uma característica humana: a capacidade de escolher, de decidir ir para e vir de um lugar para outro. Em 
2016, mais de 5,1 milhões de pessoas decidiram utilizar seu tempo livre nos CCBBs BH, DF, RJ e SP - desses, 1,122 milhão no de Brasília (CCBB, 2017).

A cultura de espetáculos que o visitante acompanha torna esse um lugar de cultura, que pode conter a dimensão espacial do cotidiano revisitado. Ao reconhecer "o lugar como uma arrumação que produz o singular" Yázigi (2001, p. 38) ressalta a responsabilidade do turismo e de seus atores para com o patrimônio local, o qual não deve se perder em meio às mudanças promovidas pelo cotidiano. Assim,

Cada lugar é, à sua maneira, o mundo. [...] Mas, também, cada lugar, irrecusavelmente imerso numa comunhão com o mundo, torna-se exponencialmente diferente dos demais. A uma maior globalidade, corresponde uma maior individualidade. [...] (SANTOS, 2006, p. 213)

Tal "individualidade" do CCBB é observada em sua composição. Tanto paisagem quanto espaço e programação, integrados, tornam o visitante protagonista, ao ponto de ele mesmo, o público, "ousar" apropriar-se dos gramados, em ações espontâneas. Trata-se da ocupação do espaço pelo cidadão, que faz daquele um lugar "todo seu" - como dizia a assinatura da campanha publicitária do Banco lançada no final de 2006 (Banco do Brasil, s/d)-, onde é possível realizar um convescote, divertir-se, tomar um café, enfim, exercer seu amplo direito de cidadania. Esta possibilidade de apropriação constante por quem o visita é reforçada pelo Centro, posto ser parte da cidade, que por sua vez também dele é parte.

Ao assenhorar-se de um espaço em que se conhecem os limites de ocupação, o cidadão confere autenticidade a um fenômeno em constante mutação. Isso porque o turismo obedece a uma lógica cuja premissa é o imaginário, o espaço "ressignificado" da e na esfera pública. Trata-se do "estranhamento" com o próprio olhar, despertando desejos e comportamentos ao deslocar-se, ou seja, ao "sair das rotinas espaciais e temporais" (Gastal e Moesch, 2007, p. 38) às quais o cidadão está habituado. Constata-se, por meio de pesquisas no próprio Centro e em sites que, em seus 17 anos de existência, não há registros de atos de vandalismo em suas instalações. Logo, o turista respeita as normas 
estabelecidas e, na eventualidade de transgredi-las, o faz assegurando-se estar no posto de anfitrião.

Cabe recorrer a Hannah Arendt e suas reflexões no que tange à esfera pública, para a qual relaciona duas acepções. Na primeira, público seria tudo o que "pode ser visto e ouvido por todos e tem a maior divulgação possível" (Arendt, 2007 , p. 59). Nesse conceito, observa-se que o CCBB preocupa-se com a difusão de si mesmo como ambiente ao qual o visitante não só é bem-vindo como também é partícipe das atividades. É o lugar próprio da experiência individual e, ao mesmo tempo, coletiva, contagiante, realizada a partir da percepção que se tem da realidade, daquilo que se experimenta. Na segunda definição, a filósofa tem como público o que é "comum a todos nós e diferente do lugar que nos cabe dentro dele" (op.cit., p. 62). Estabelecendo-se a construção do Centro Cultural para todos, a partir de uma programação que satisfaça o maior número de pessoas, não importando classes sociais, estilos, seu principal mecenas procura encontrar vínculos que possam conduzir as pessoas àquele lugar, fazendo com que dele se apropriem, como espaço público, mesmo sabendo-o privado.

As ampliações sofridas pelo CCBB ao longo dos anos são exemplo de "que o espaço é constantemente modificado pela história", como nos lembra Yázigi (2001, p. 40). E é em uma constante mutação que o Centro concentra sua força e liderança. $O$ frequentador é partícipe dessa organização ao contribuir para que a cidade (lugar de sua residência ou não) tenha um dos 100 centros culturais/museus mais visitados do mundo desde 2011 (The Art Newspaper, 2012, p. 37).

Como assevera Angelo Serpa (2014, p. 133), é especialmente "a história pessoal do indivíduo" que decreta a relação dele com seus espaços habituais. É como se o CCBB, com sua programação e ambiente, deixasse de ser um castelo intangível. Pascale Auraix-Jonchière, ao tratar sobre a dualidade acolhida e hostilidade do castelo, frisa que esse espaço no qual o turista sente-se seguro e protegido acaba por revelar processos que excedem a sociabilidade: 
[...] Protegido pelo espanto que suscita tanto quanto por sua arquitetura eminentemente defensiva e pela geografia hostil que o circula, ele só pode ser o teatro de um estranho simulacro de hospitalidade, encenação de uma fatídica confrontação do eu consigo mesmo. [...] (AuraixJonchière, 2011, p. 477)

E como a pesquisa aborda um centro cultural, essa relação de autoconhecimento do visitante passa, necessariamente, por ela, a arte, que, no CCBB, seria, nesse sentido, também um "lugar":

As famosas linhas curvas de Niemeyer, num projeto leve e funcional, aliam-se à paisagem aberta do Planalto para criar um ambiente agradável, perfeito para apreciação de manifestações culturais. (Banco do Brasil, s/d)

A professora Zeny Rosendhal (2007) recorre ao geógrafo W. Norton em seu Cultural geography: themes, concepts, analyses para afirmar que a "criação de lugares é um ato social e, portanto, os lugares diferem porque as pessoas assim os construíram". Nessa acepção de lugar como "fenômeno interrelativo", observa-se o turista como consumidor da cultura artística no CCBB. Acrescenta-se a questão relativa à ritualização que permeia todo esse cenário, com horários marcados, assentos delimitados, modo de comportamento nas salas etc. O ritual, esse conjunto de formalidades e pleno de valor simbólico, é praticado pelo CCBB desde o convite ao frequentador, no mundo virtual, à forma de receber, com liberdade e serviços oferecidos.

Numa sociedade fascinada por aparências, o CCBB age de modo a tornar-se um lugar para o qual todos são bem-vindos, numa tentativa de manter sua imagem hospitaleira. Não se deve, contudo, perder de vista os bastidores, a intrínseca relação - e, por que não, subserviência - à estratégia de marketing da instituição financeira que o mantém. Pode-se, então, afirmar que o CCBB seria monopolizado por meio de coerção e violência simbólica instituídas pelo discurso do Banco? No entanto, cada ação gera uma reação que pode implicar em agradar a alguns e desagradar a outros. 


\section{UM CENTRO CULTURAL NA CAPITAL FEDERAL}

A escolha dos edifícios que abrigam os quatro centros culturais Banco do Brasil foi sempre pautada na revitalização da região, na acessibilidade e na valorização de importantes centros históricos. O CCBB Brasília é o único que foge à regra, ao situar-se fora da área central urbana, no Setor de Clubes Sul, Trecho 2, Edifício Tancredo Neves. O objetivo de sua constituição, porém, passava pela integração.

O parecer [...] de criação do CCBB Brasília, datado de 9 de fevereiro de 2000, [...] expressava uma conotação urbanística, ao assinalar o potencial do prédio escolhido para acolher o projeto, o Edifício Tancredo Neves, complexo projetado por Oscar Niemeyer para sediar a área de gestão de pessoal do Banco do Brasil, construído ao final da década de 1980, por se localizar "em área que atualmente está sendo reurbanizada - Projeto Orla o que facilitará o acesso por transporte público". (Vieira, 2006, p. 211)

O projeto arquitetônico do complexo foi realizado pelo arquiteto Oscar Niemeyer com o intuito de abrigar o Centro de Formação do Banco do Brasil (Cefor). A proposta original era, assim, voltada, exclusivamente, para o desenvolvimento da educação bancária dos funcionários da instituição financeira. Nem de longe se pensava que um dia poderia vir a ser um centro cultural. $O$ acesso seria facilitado com a implantação, pelo Governo do Distrito Federal, do Projeto Orla (Plano de Ordenamento e Estruturação Turística de Brasília), concebido originalmente para revitalizar o Lago Paranoá, o qual deveria ser

[...] composto por 11 pólos, planejados para funcionarem tanto no período diurno como noturno e um Calçadão, designado de Alameda que os interligam. Estão previstas várias utilizações para estes pólos, que vão desde a hospedagem às culturais, passando pelo comércio e lazer, com oferta de ambientes atrativos e de meios agradáveis de estada, tudo para aumentar o tempo de permanência do turista na cidade. (Governo do Distrito Federal, 1995, p. 11)

No entanto, o Projeto Orla jamais foi implantado. O Cefor, por outro lado, foi inaugurado em 1993. Todavia, as obras previstas no traçado original de Niemeyer não foram concluídas, como demonstra a maquete (Figura 1) que fica à entrada da administração do CCBB Brasília, no segundo andar do edifício. 


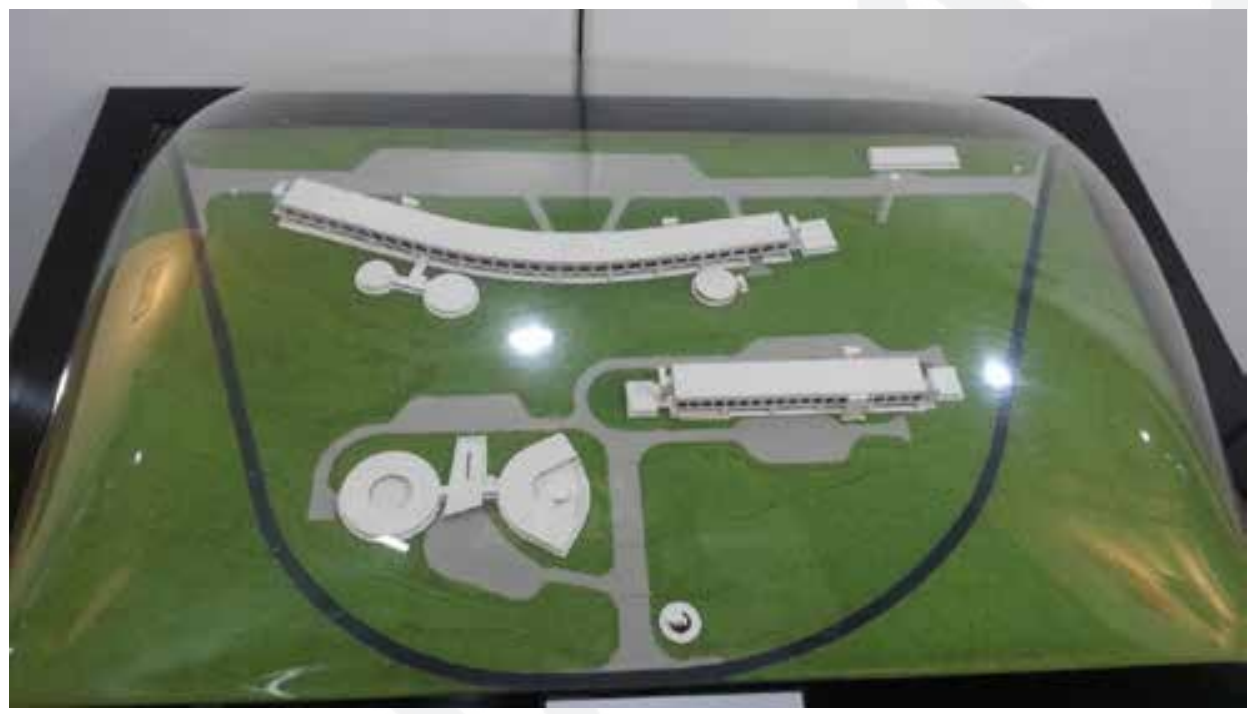

Figura 1: Maquete do projeto original de Oscar Niemeyer para o Centro de Formação do Banco do Brasil, disponível na entrada administrativa do CCBB DF. Foto da autora

Nos anos 1990, o Banco do Brasil vinha de uma experiência bem-sucedida no Rio de Janeiro, no que tange à sua aposta para a área cultural. Desde que fora inaugurado, em 1989, o CCBB RJ tornara-se referência no cenário nacional pela qualidade, diversidade e regularidade da programação. O modelo levou o referido Centro a desenvolver um guia para criação e utilização de espaços culturais para todo e qualquer empreendedor com recursos para tal. $\mathrm{O}$ manual, denominado "Guia para formação e utilização de espaços culturais" (CCBB, 1997), traz, com certo detalhamento, indicações de como uma instituição deve instalar e gerir um ambiente cultural, com informações desde a escolha do local, passando por dicas de revestimentos de paredes, iluminação, organização do espaço, realização de eventos e até formação de pequenas bibliotecas. Não se pode afirmar peremptoriamente que foi um dos norteadores para os projetos de CCBB que se seguiram. Por outro lado, uma instituição com grande apreço por suas boas práticas e realizações não poderia desperdiçar as próprias experiências de sucesso.

Paradigma de marketing cultural e, especialmente nos casos de Rio de Janeiro e São Paulo, para a requalificação dos centros urbanos, indubitavelmente, o 
Centro Cultural Banco do Brasil está presente em qualquer análise ou consideração que se faça sobre museus e/ou centros culturais no Brasil. Mas o que, afinal, teria levado o maior banco do País a criar um espaço próprio voltado para as artes? Parte da resposta encontra-se no Guia, o qual indica que, para manter-se no mercado, não basta a uma empresa prestar ao consumidor serviços de qualidade; nos tempos modernos, ela precisa "mostrar-se indispensável, integrada ao meio, corresponsável pelo ambiente onde atua" e que "a realização de eventos que valorizem as manifestações artísticas e culturais nas diversas regiões do País" é uma das mais exitosas formas "de se estreitar o nível de relacionamento com a comunidade" (op.cit., p. 3). Fato é que, ao dedicar à cultura um amplo espaço, o BB identifica-se com ela - e com o lugar que esta ocupa no imaginário do cidadão, construindo sua imagem de empresa cidadã e hospitaleira.

Em meio a essa espiral, o CCBB surge como a versão humanizada da instituição financeira, que configura uma versão identitária para o Banco, desconectada dos grandes interesses corporativos e econômicos do capital. Ao criar uma forma de relação e interação por meio de um centro cultural, o Banco molda outra racionalidade discursiva para a cidade e seus visitantes. Dessa maneira, o Centro se insere no contexto imaginativo como um espaço no qual é possível mesclar imagens positivas - porque cria um lugar de sociabilidade para aquele que o visita - e negativas - pois é um espaço construído por um discurso que não se deixa apropriar de fato, na medida em que somente o hospitaleiro é quem define as regras de habitá-lo. Embora o visitante alimente a ideia de que o espaço pertence a ele, o que ele vive de fato é uma espécie de simulacro de territorialização.

Em 12 de outubro de 2000, no mesmo dia em que o Banco do Brasil completava 192 anos, nascia, na capital federal, o segundo CCBB do País - o terceiro foi implantado em 2001, na capital São Paulo (SP), e o último em 2013, em Belo Horizonte (MG). Com assinatura de Alda Rabelo Cunha, o projeto paisagístico ressaltava o conjunto arquitetônico de concreto, projetado por Oscar Niemeyer, composto por dois andares, assentado sobre pilotis e dividido em módulos. 


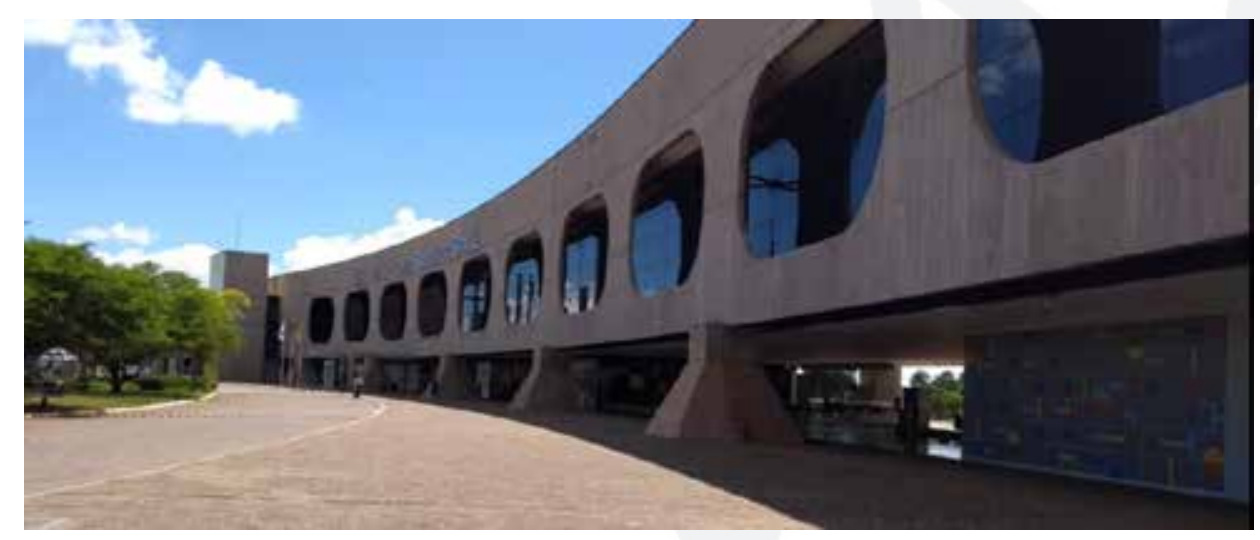

Figura 2: Panorâmica do Edifício Tancredo Neves, que abriga o CCBB DF. Foto da autora

Era, porém, preciso adaptar o prédio projetado para ser centro de treinamento interno para receber exposições, apresentações de artes cênicas e musicais. Foram cinco meses de obras, com investimento de "R\$1,4 milhão ( $R \$ 600$ mil a menos que o planejado)" (Maciel, 2000, p. 20).

Reportagem do jornal Correio Braziliense da época, intitulada "Por dentro do Centro", registra a dimensão da estrutura que surgia no planalto central. No texto, o jornalista Klecius Henrique oferece dicas de como chegar, programação, e ainda ilustrações para melhor identificar os espaços ao público que, pela primeira vez, entraria em contato com o CCBB Brasília.

O caminho pode não ser dos mais fáceis, mas vale a pena destrinchá-lo para chegar ao Centro Cultural Banco do Brasil - Brasília. Localizado no trecho 2 do Setor de Clubes Esportivos Sul, onde funciona o Centro de Treinamento do Banco do Brasil, prédio projetado por Oscar Niemeyer, o mais novo espaço cultural da cidade abre as portas hoje para o público. (Henrique, 2000, p. 1)

Nos três parágrafos seguintes de seu retrato sobre aquela novidade, o periodista demonstra que as preocupações com a distância e com a mobilidade urbana, com o acesso, já se faziam presença. Destaque para a solicitação do CCBB ao Departamento Metropolitano de Transportes Urbanos por melhores serviços para a região, pois o Setor estaria "localizado em área malservida de ônibus". O repórter ainda reforça: "Para quem tem carro, a história é diferente. 0 estacionamento, com 500 vagas, 
é grátis e tem segurança garantida pelo CCBB, que fará controle de entrada e saída dos carros." (op.cit.)

Especula-se que essa característica tenha contribuído para o viés "elitista" dado ao Centro, especialmente em seus primeiros anos de existência. Apesar de amplo e com uma intensa programação, o CCBB de Brasília chegava tímido, ocupando, em princípio, apenas parte do Edifício Tancredo Neves: duas estruturas cilíndricas e um vão central arejado e livre de paredes.

\section{[...]Importa registrar que o projeto do CCBB Brasília era bem mais acanhado que o de São Paulo, porquanto originalmente se circunscrevia a duas galerias, praticamente. O sucesso do empreendimento, no entanto, levou à expansão que o fez absorver o anterior auditório da Diretoria de Gestão de Pessoas, para instalação do teatro, e obter mais salas para exposições. (Vieira, 2006, p. 211)}

$E$, assim, o CCBB DF se apresentava à cidade com intensa programação de artes plásticas, artes cênicas, música, ideias e programa educativo - uma de suas iniciativas mais bem-sucedidas de arte-educação. Faltaria apenas a sala de cinema, inaugurada em 2003, com a mostra Brasília 24 Quadros, com exibição de filmes realizados na cidade de 1962 até 2002.

Por sua capilaridade, não interessava ao Banco ter planejado um centro cultural sem visitantes. Os resultados positivos não demoraram e, dois anos após sua inauguração, recebia a Comenda da Ordem do Mérito Cultural do Distrito Federal pelos relevantes serviços prestados à cultura brasileira. Entre outubro de 2000 e setembro de 2002, o Centro havia recebido mais de 300 mil espectadores, para os seus 713 eventos realizados. Só o Programa Educativo havia sido responsável por recepcionar cerca de 89 mil estudantes de escolas públicas e privadas (Cultura e Mercado, 2002). A acolhida caracterizou-se, desde sempre, como um aspecto peculiar do Centro. 


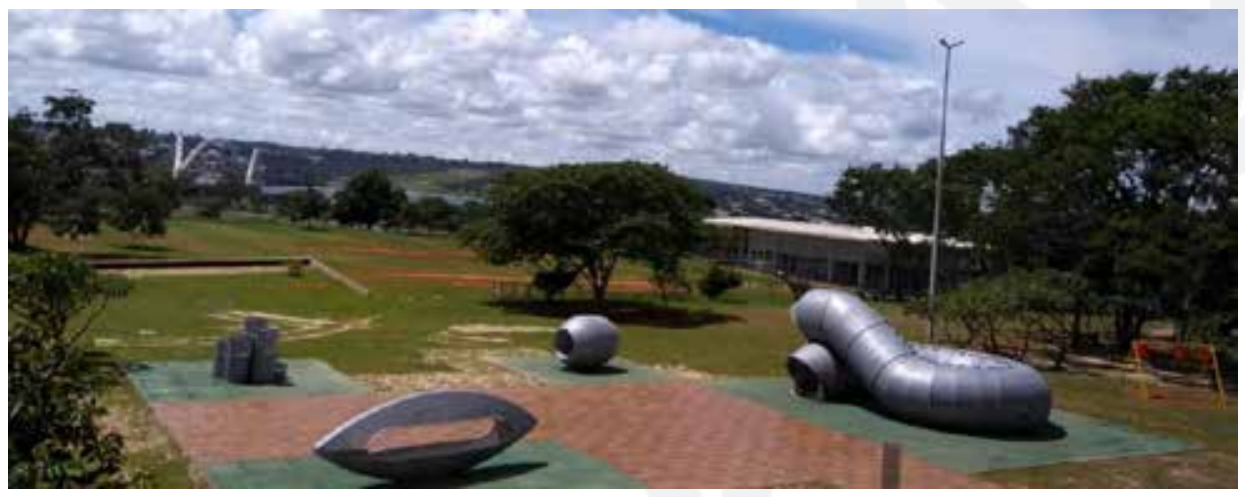

Figura 3: Vista panorâmica de Casulo, de Darlan Rosa - mostra permanente do CCBB DF tendo, ao fundo, o pavilhão de vidro (não previsto no projeto original). Foto da autora

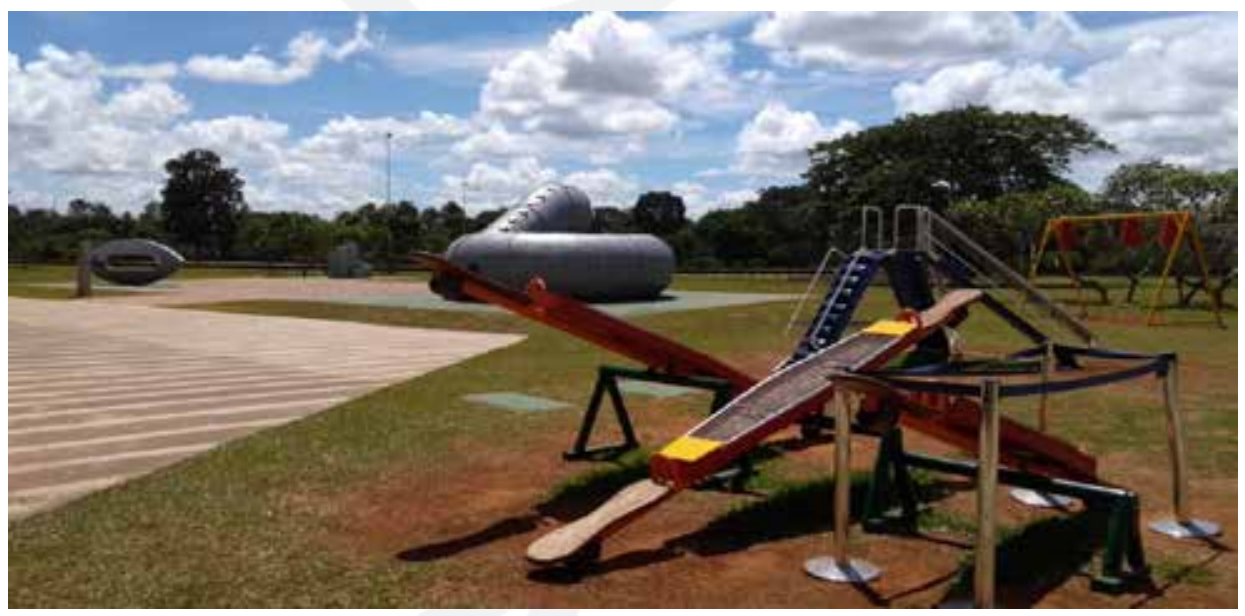

Figura 4: Mostra Casulo sob outro ângulo. Foto da autora

Com o sucesso dos números, eram inevitáveis os planos de crescimento. E, ao longo dos anos, o espaço foi ganhando novas estruturas e projeções: uma área localizada em um dos módulos do edifício, onde atualmente trabalham os funcionários que coordenam as atividades, outras duas galerias, outro teatro, uma sala de cinema, pavilhão de vidro. No ambiente que convida à convivência, a gastronomia se faz presente por meio de um bistrô e uma cafeteria, enquanto a livraria oferece cardápio para ocupar as mentes ${ }^{2}$. Na área externa, uma exposição permanente e interativa, Casulo, composta de

\footnotetext{
${ }^{2}$ Os espaços gastronômicos e a livraria são geridos por empresas privadas, cujas concessões são obtidas via concorrência pública: http://www.bb.com.br/editaislicitacoes.
} 
obras de Darlan Rosa, que animam o dia-a-dia das crianças (Figuras 3 e 4), uma instalação, Améfrica (Figura 5), de Denise Milan, além de redes de balanço e bancos com espaço para leitura e vista para o lago.

\begin{abstract}
Prédios monumentais de Niemeyer com grandes jardins há vários em Brasília. No caso deste, um dos ocupantes mudou a história do monumento. É o Edifício Tancredo Neves. Foi construído para ser o Centro de Treinamento do Banco do Brasil e ainda é! Teve Lula despachando e tomando decisões importantes para o país durante quase um ano e meio em uma ponta do prédio, enquanto o então presidente esperava a reforma do Palácio do Planalto. Mas é o espaço que ocupa apenas a outra ponta do edifício que mexe com a cidade. Virou referência cultural e afetiva com suas salas de exposição, teatro, cinema e espetáculos ao ar livre e que fazem parecer que é dono do pedaço, e às vezes é. (Souza, 2011)
\end{abstract}

Brasília, a cidade, está intrinsecamente ligada ao seu arquiteto, Oscar Niemeyer. As anotações de Souza remetem a essa quase onipresença e conta, em poucas palavras, as transformações sofridas pelo prédio batizado com o nome de Tancredo Neves, o primeiro presidente civil eleito (por eleições indiretas) após 20 anos de ditadura militar. É preciso atualizar, porém, duas referências dadas acima. A primeira, relativa à múltipla função do CCBB. Entre 2009 e 2010, parte do edifício abrigou o gabinete presidencial de Luís Inácio Lula da Silva, tendo em vista a primeira grande restauração do Palácio do Planalto, desde que fora inaugurado, em 21 de abril de 1960.

Antes, porém, entre novembro de 2002 e janeiro de 2003, salas abrigaram o chamado governo de transição, propiciado por um arranjo político entre a administração de Fernando Henrique Cardoso e a aliança vencedora das eleições de 2002 (PT-PL). O fato se repetiu na passagem do segundo governo Lula para o primeiro mandato da presidenta Dilma Roussef, entre novembro de 2010 e janeiro de 2011.

A outra atualização ao texto de Souza refere-se à destinação do prédio. Entre meados de 2013 e início de 2015, todo o centro de treinamento foi transferido para um novo imóvel, na zona central de Brasília. O espaço desocupado em todo o primeiro andar do Edifício entrou em obras em outubro de 2013 para 
abrigar as instalações do "Museu Banco do Brasil - História, Cultura e Cidadania", inaugurado em 12 de outubro de 2016.

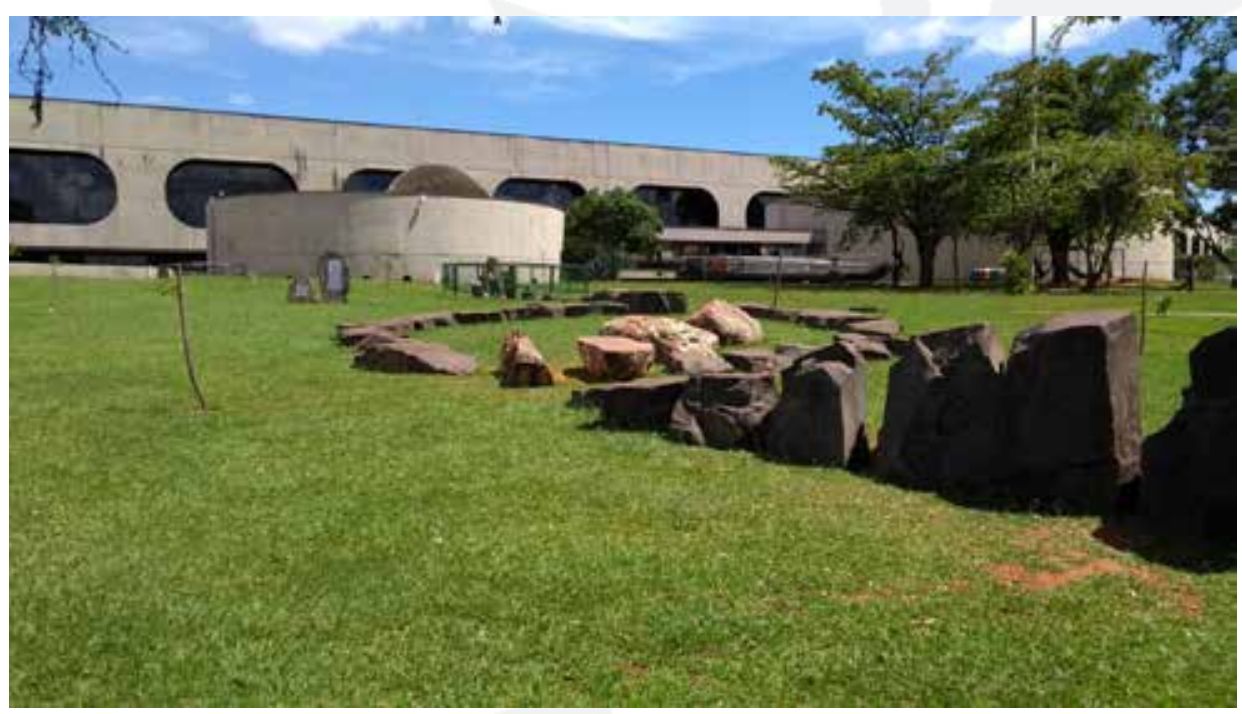

Figura 5: Améfrica, de Denise Milan - mostra permanente do CCBB DF. Foto da autora

Tem-se, assim, o Edifício Tancredo Neves, idealizado para abrigar apenas uma parcela dos funcionários da instituição financeira, hospedando, em suas instalações, um espaço para apresentações artísticas, o qual se tornou "referência cultural e afetiva" (Souza, 2011) para os cidadãos brasilienses, pela programação que oferece aos seus visitantes. "A hospitalidade desapropria os limites da propriedade" (Montandon, 2011, p. 35) - e o sisudo prédio de concreto, quem diria, passava a ser visto, por quem a ele se achegava, como um generoso anfitrião, capaz de sacrifícios pelo bem do seu convidado.

O sacrifício do hospedeiro, primeiramente, custa-lhe seu próprio nome. Poucos se referem ao local pelo seu nome oficial, Edifício Tancredo Neves. Todos os que para ali se dirigem vão ao $\mathrm{CCBB}$, ao hóspede que tomou as chaves da casa e apropriou-se do lugar de maneira cativante para todos os que o frequentam. Essa imolação cria um vínculo interno com o visitante que opera no âmbito das afirmações da instituição financeira, que por sua vez passa a existir como uma empresa cidadã na imaginação do seu hóspede. Ao operar 
com este capital simbólico do bom hospedeiro, o CCBB mobiliza o imaginário social, ao criar uma arquitetura material e intelectual de um território subsumido às práticas sociais do visitante.

\begin{abstract}
A paisagem não se cria de uma só vez, mas por acréscimos, substituições; a lógica pela qual se fez um objeto no passado era a lógica da produção daquele momento. Uma paisagem é uma escrita sobre a outra, é um conjunto de objetos que têm idades diferentes, é uma herança de muitos diferentes momentos. (Santos, 2008, p. 73)
\end{abstract}

A paisagem, no CCBB, obedece à lógica do contexto. À administração cabe o uso regular, organizando espetáculos diversos que por sua vez incentivarão cada vez mais o afluxo de pessoas. Já quem busca o lazer com amigos, familiares e afins, além de interagir com a programação oferecida, ainda vê, ali, a possibilidade de gerir ele mesmo o ambiente, promovendo encontros informais. O CCBB, desse modo, vai se erigindo como um lugar de força inovadora e dinâmica que realiza, de maneira singular, o discurso que o projeta como lugar de variedades em que se materializam oportunidades de experiências. Configurado por uma dialética entre o imaginário de possibilidades e a pseudo probabilidade de apropriação do espaço, o CCBB pertence à cidade e a cidade a ele pertence.

Outros exemplos de apropriação são os curtas-metragens produzidos a convite do próprio Centro. Ao longo de 2011, pairava a sombra da profecia de Nostradamus de que o mundo iria acabar em 2012. Nos CCBBs, as redes sociais ainda não contavam com tantos seguidores. Uma ideia reuniu os três centros existentes à época (CCBB DF, CCBB RJ e CCBB SP) na divulgação e efetivação das respectivas páginas. Trata-se da promoção "Curta 2012 no CCBB", um concurso de abrangência nacional, para maiores de 18 anos (Banco do Brasil, 2011). A participação previa a produção de um curta-metragem de até 1 (um) minuto com o tema " 2012 ".

O curta deveria, necessariamente, ser filmado nas dependências de um dos CCBBs e publicado na fan page do Centro onde a gravação fosse realizada. Haveria dois vencedores por CCBB. Cada um ganharia uma viagem, com acompanhante, para conhecer os outros dois centros, além de um Kit, 
contendo mala de viagem, camisetas e tablet. Dentre as regras, somente os participantes que curtissem as fan pages dos três CCBBs no Facebook e seguissem os três perfis dos CCBBs no Twitter estariam aptos a participar. Ou seja, havia um claro objetivo de ampliar o número de acessos às contas na rede social dos centros. Para tanto, públicos geralmente excluídos de promoções não estavam impedidos de participar ("funcionários, contratados, estagiários e terceirizados do Conglomerado"). No entanto, venceriam os dois vídeos mais bem avaliados por comissão técnica e não com maior número de "curtidas", o que demonstra preocupação não somente com o aumento de público em suas páginas, mas também com a qualidade do material apresentado no concurso.

Um dos ganhadores, "Em 2012 eu vou viver no CCBB", de Gustavo Serrate, ao som de Ergo Phizmiz, mostra um homem que começa o dia na obra "Casulo", de Darlan Rosa, verificando a programação no livreto do CCBB. Em seguida, faz ginástica; bebe água; come um fruto colhido diretamente de uma árvore; sai de um dos sanitários, se seca, como se tivesse acabado de se banhar; entra no cinema para uma sessão; deita-se debaixo de uma árvore, nem tão frondosa, com um guarda-chuva aberto, que o abrigam de uma pancada de chuva; passa pela fila da bilheteria; retira uma sacola/pertences do armário; observa uma pessoa lendo o que parece ser o cardápio do bistrô; e retorna para o "Casulo", nele se deitando, como se fosse ali dormir. Vale citar, ainda, que o autor assim descreve o trabalho: "'Eu vivo no CCBB", a força de expressão faz jús a (sic) realidade. Eu sempre estou por lá para pegar um filme, ver uma exposição, tomar um café." (Serrate, 2012). Por outro lado, o título da música que o acompanha, "Trick me" - "Engana-me", numa tradução livre -, deixa claro que é possível que tudo não passe do mito da caverna de Platão.

Ao propor habitar o que não é habitável, o artista mostra a natureza excêntrica do espaço, ao mesmo tempo em que provoca no espectador a consciência desse mesmo espaço. Como demonstra o vídeo, o Centro, com tudo o que o constitui, faz o indivíduo querer viver naquele ambiente cercado de natureza e 
arte por todos os lados. É sua casa, onde se aprende a falar, brincar, amar, comer, se relacionar, mandar, obedecer.

O segundo vídeo, "2012", com composição musical dos próprios criadores do curta, Artur Paschoali e Amanda Apen, traz um jovem vestindo figurino, usando óculos e corte de cabelo que remetem aos anos 1970, o que denota a atemporalidade dada ao espaço. Ele caminha por diversos ambientes interpretando as cenas sugestivas da letra da canção abaixo reproduzida:

Em 2012 tudo pode acontecer com você / Dizem que o mundo vai acabar / Dizem que se você não se cuidar / Comida de zumbi você pode virar / Mas isso não importa se você lembrar / Que o planeta não vai parar de girar / Enquanto todo mundo conseguir se amar / $E$ de mãos dadas festejar! / Faça um pedido / Pra 2012! (Paschoali e Apen, 2012)

Nesse curta, os criadores apresentam a tão ensejada liberdade - pelos jovens. Naquele espaço, ele é livre e pode construir a própria história.

Aos poucos, o turista vai conhecendo e se reconhecendo no espaço geográfico, num complexa inter-relação social, de interiorização psicologizante, dotada de simbolismo, e, principalmente, de apropriação do lugar, promovendo nele sua própria manifestação, em uma marcante forma de identificação e, consequentemente, prática social.

\section{CONCLUSÃO}

O Banco do Brasil possui quatro centros culturais nas cidades de Belo Horizonte (MG), Brasília (DF), Rio de Janeiro (RJ) e São Paulo (SP), sendo três deles situados na região central das respectivas capitais e com acesso facilitado a quem se aproxima. O CCBB Brasília, nesse ponto, possui peculiaridades. Sua origem remonta a um projeto muito maior, que visava à integração com a cidade. É um lugar pelo qual não se passa, simplesmente. Ele não está no caminho da casa ou do trabalho das pessoas; ao contrário, é um local para onde é preciso se deslocar com o intuito de lá estar. 
Trata-se de espaço dotado de personalidade, de infraestrutura básica, com atrativos qualificados. Como assinala Milton Santos (2006, p. 213), ao mesmo tempo em que cada lugar é o mundo, "à sua maneira", ele é "exponencialmente diferente dos demais". E o número de visitantes conquistados, que a cada dia se interessam pelo CCBB DF, parece comprovar que o Centro encontrou o seu cerne ao quebrar paradigmas, já que houve um tempo em que era identificado pelo visitante como um espaço destinado ao turista elitista, em função da dificuldade de se chegar ao local e pela programação oferecida, considerada de baixo apelo popular e voltada para públicos com acesso a pesquisas e a formas diferenciadas de arte.

Como vimos, de modo especial com o mesmo Santos e com Yázigi, tais ampliações de concepções acabam por designar os espaços tensionados pela demanda do visitante em territorializar e reterritorializar o CCBB. Por outro lado, percebe-se que as constantes mudanças também são maneiras de o Centro integrar-se às espacialidades criadas nos processos de interação estabelecidos de maneira a compor um discurso no qual ele se firma como o anfitrião, aquele que, mesmo atendendo as demandas do hóspede, é quem define como e quando os pleitos serão atendidos.

Não se deve esquecer que o CCBB é, ele próprio, um hóspede que se tornou anfitrião. Para tanto, modificou espaços, dando-lhes novos usos e instrumentos no intuito de receber, ratificando a premissa de que "todo território geográfico implica um território da alteridade." (Grassi, 2011, p. 45)

No âmbito de quem se responsabiliza por sua manutenção, observa-se que, identificar-se com o cliente por meio de atributos não-negociais ou simbólicos que sejam representativos do seu quadro de valores é uma maneira de a marca Banco do Brasil se posicionar no mercado. E uma casa atraente, arrumada e singular, sede do início de renomados eventos, pode, certamente, significar um começo favorável. Em uma espécie de dialética relacional, o Banco internaliza no imaginário social seu papel de mecenas cultural, 
estabelecendo uma imagem inversamente decomposta da entidade financeira que está em consonância com os ditames do mercado capitalista.

Nesse ínterim, o CCBB constrói sua identidade enquanto lugar e como espaço que recebe grupos e indivíduos, tornando-se um ambiente em que se efetiva a prática turística.

\section{REFERÊNCIAS CITADAS}

ARENDT, Hannah. A condição humana. Rio de Janeiro: Forense Universitária, 2007.

AURAIX-JONCHIÈRE, P. Castelo: entre acolhida e hostilidade. In: MONTANDON, Alain (org.). O livro da hospitalidade: acolhida do estrangeiro na história e nas culturas. São Paulo: Senac, 2011. p. 471-480.

BOTTON, Alain de; ARMSTRONG, John. Arte como terapia. Rio de Janeiro: Intrínseca, 2014.

CCBB. Guia para formação e utilização de espaços culturais. Rio de Janeiro: CCBB, 1997.

GASTAL, Susana; MOESCH, Marutschka Martini. Turismo, Políticas Públicas e Cidadania. São Paulo: Aleph, 2007.

GOVERNO DO DISTRITO FEDERAL. Revista Projeto Orla, Brasília XXI. Brasília: GDF, 1995.

GRASSI, Marie-Claire. Hospitalidade: Transpor a soleira. In: MONTANDON, Alain (org.). O livro da hospitalidade: acolhida do estrangeiro na históra e nas culturas. São Paulo: Senac, 2011. p. 45-53.

HENRIQUE, Klecius. Por dentro do Centro. Correio Braziliense, Brasília, 12 de outubro de 2000, p.1.

MACIEL, Nahima. Endereço das artes. Correio Braziliense, Brasília, 11 de outubro de 2000 , p.20.

MONTANDON, Alain. Prefácio: Espelhos da hospitalidade. In: (org.). O livro da hospitalidade: acolhida do estrangeiro na história e nas culturas. São Paulo: Senac, 2011. p. 31-37.

OLIVEIRA, Adelaide. O CCBB como anfitrião: uma reflexão sobre o turismo e a hospitalidade a partir do discurso proferido pelo Centro Cultural Banco do Brasil Brasília no site e no Facebook. Dissertação apresentada ao 
Centro de Excelência Turismo da Universidade de Brasília/UnB, março de 2016.

ROSENDAHL, Zeny. Cultura, turismo e identidade. In: NUSSBAUMER, Martin G. (org.). Teorias \& políticas da cultura: visões multidisciplinares. Salvador: EDUFBA, 2007. p. 245-256.

SANTOS, Milton. A Natureza do Espaço: Técnica e tempo, razão e emoção. São Paulo: Editora da Universidade de São Paulo, 2006.

SANTOS, Milton. Metamorfoses do espaço habitado: fundamentos teórico e metodológico da Geografia. São Paulo: Hucitec, 2008.

SERPA, Angelo. O espaço público na cidade contemporânea. São Paulo: Contexto, 2014.

SOUZA, Zuleika de. Assim... Bem CCBB. Revista do Correio, Brasília, 24 de junho de 2011.

VIEIRA, Marco Estevão de Mesquita. Distinção, cultura de consumo e gentrificação: O Centro Cultural Banco do Brasil e o mercado de bens simbólicos. Tese apresentada ao Departamento de Sociologia da Universidade de Brasília/UnB, fevereiro de 2006.

YÁZIGI, Eduardo. A alma do lugar: turismo, planejamento e cotidiano. São Paulo: Contexto, 2001.

\section{Websites}

BANCO DO BRASIL. Espaços - CCBB DF. Centro Cultural Banco do Brasil, s/d. Disponível em:

http://www.bb.com.br/portalbb/page509,128,10136,0,0,1,1.bb?codigo Noticia $=18050 \&$ codigoMenu=10675. Acessado em 11 de dezembro 2017.

BANCO DO BRASIL. Regulamento da Promoção "Curta 2012 no CCBB". Centro Cultural Banco do Brasil (2011). Disponível em: http://www.bb.com.br/portalbb/page512,128,10189,1,0,1,1.bb?codigo Menu=9926\&codigoNoticia=32678. Acessado em 11 de dezembro 2017.

CCBB. Sobre o Centro Cutural Banco do Brasil (2017). Disponível em: http://culturabancodobrasil.com.br/receptivo/sobre-o-ccbb/. Acessado em 08 de dezembro 2017.

CULTURA E MERCADO. CCBB Brasília completa 2 anos: Cultura e Mercado (2002). Disponível em: http://www.culturaemercado.com.br/site/noticias/ccbb-brasiliacompleta-2-anos/. Acessado em 11 de dezembro 2017. 
PASCHOALI, Artur; APEN, Amanda. 2012. Youtube (2012). Disponível em: https://www.youtube.com/watch?v=i-ScDlaOD4c. Acessado em 11 de dezembro de 2017.

SERRATE, Gustavo. Em 2012 vou viver no CCBB: Youtube (2012). Disponível em: https://www.youtube.com/watch?v=cHS4l45LakE. Acessado em 11 de dezembro 2017.

THE ART NEWSPAPER. Visitor Figures: Exhibition \& museum attendance figures 2011. The Art Newspaper (2012). ISSN 234. Disponivel em: http://www.museus.gov.br/wpcontent/uploads/2012/03/ArtNewspaper_Ranking2011.pdf. Acessado em 14 de dezembro 2017. 